\title{
Factor That Influence To Acceptance M-Learning among Jordanian Students
}

\author{
Saleem Issa Al Zoubi ${ }^{1}$, Ahmad Issa Al Zoubi ${ }^{2}$ \& Mohmmad Al Zoubi ${ }^{3}$ \\ ${ }^{1}$ Computing Technology and Control System Department Irbid National University, Jordan \\ ${ }^{2}$ Department of Business Administration Toledo College, Jordan \\ ${ }^{3}$ Al-Madinah International University, Jordan
}

Correspondence: A. Saleem Issa Al Zoubi, Computing Technology and Control System Department Irbid National University, Jordan. E-mail: ahmadalzoubi37@gmail.com

Received: July 11, 2018

doi:10.5539/cis. v12n1p53
Accepted: August 16, 2018

Online Published: January 18, 2019

URL: https://doi.org/10.5539/cis.v12n1p53

\begin{abstract}
The research aims to examine critical factors that influence the acceptance and use of M-learning among Jordanian student. This study integrates technology acceptance model (TAM) with service quality factor. The primary data were collected from 487 valid questionnaires, which were distributed, to random Jordanian students in four cities. The analyses of the gathered data employed the (SPSS). The validity of the final overall model was evaluated using the statistics and acceptable fit of the measurement model to the data has been demonstrated. Based on the outcomes, the factors with the highest direct effect on Intention to use M-learning appeared to be Attitude toward using M-learning, while the factor with the highest indirect effect on Intention to use M-learning appeared to be Compatibility. The main findings of the study are: trust factor has a significant stronger impact on PEOU and PU. PEOU and PU have the stronger impact on customers' attitude, which in turn influences students' intention to use $\mathrm{M}$ - learning services.
\end{abstract}

Keywords: M-learning, acceptance, education, TAM

\section{Introduction}

Mobile learning or m-learning has recently evolved into a real means of education (Stead, 2005). This has been proven through the growth and impact of groundbreaking technology and implementation of m-learning in the last decade. The growth and development of m-learning has also been in line with the evolution of online world (Alzaza \& Yaakub, 2011), and the rapid development of mobile technology has propelled the creation of wireless $\mathrm{m}$ learning on mobile devices (Pulla, 2013). Further, in line with the development of means of communication, the process of learning has also changed where it has evolved from the conventional face-to-face method to the distance learning and e-learning (Azizan, 2010).

\section{Literature Review}

Researchers have shown great interest on the success or failure of mobile learning and have so far been mainly investigating into the matter post-trial (Shuler et al., 2012; Embi \& Nordin, 2013). As such, before m-learning is implemented, it is necessary to probe into the elements that impact the acceptance of students, such as factors of acceptance, limitations and requirements (Mtebe \& Raisamo, 2014). This is done to help ensure that the money and time invested into the implementation of the system are well spent and hopefully would generate success (i.e. in terms of students' acceptance). Furthermore, the investigation could assist universities in to align their strategic planning with the demands of the students - all of which would lead to better investment in technology (Al-matari et al., 2013; Embi \& Nordin, 2013).

Further, when factors associated to acceptance of mobile learning are identified, the universities implementing this learning method can improve on the delivery of services to the students. Apart from that, when these factors are incorporated into the business process, education and learning will be more efficient and there will be an increase in students' loyalty (Alzaza \& Yaakub, 2011; Pimpaka, 2013; Iyamu \& Mtshali, 2013 Alzubi et al., 2017). However, according to Al-matari et al., (2013), the university would have to expect the potential factors that may influence students' intention and understand how the factors could encourage them to use m-learning in order to invest the developments of mobile service and content properly. Nonetheless, it would be hard for the students to get the 
information if they fail to accept a new technology.

Among the factors that are found to be affecting the acceptance of students towards m-learning are service quality, social influence and cultural differences. Additionally, the factor of service quality also affects users' acceptance intention. Furthermore, according to Liu and Han (2010) it service quality also shows a positive causal relationship between the satisfaction of user concerning a web portable, as well as the perceived overall quality of service. Also, according to Abu-al-aish and Love (2013), service quality has an effect on users' acceptance intention. Hence, the service quality factor is paying an important role for students' attitude towards using m-learning. Moreover, understanding the nature of services quality factor will support institution of higher education to provide high quality services to learners and develop their education and education strategic plans.

\section{Theoretical Background}

Technology acceptance model have been formulated in order to explain the determining factors of acceptance among user in a wide array of end-user computing technologies (Davis, 1986). This model was based on Ajzen and Fishbein's (1980) theory of reasoned action or TRA. Additionally, since TRA is a model that is well established, many scholars various fields employ it in explaining and predicting human behaviour. Originally, TAM consisted of five components namely, behaviour system use, perceived ease of use (PEOU), attitude toward using (ATU), behavioral intention to use (BI), and perceived usefulness (PU). Specifically, as indicated by Davis (1989) PEOU represents the degree to which a user believes that using a particular service would be effortless, while PU means the degree to which an individual perceives that using a particular system would improve the performance of his or her job. PEoU and PU are the two most important factors for system use and in fact, according to Liu and Han (2010) and Alzubi et al., (2017) these two elements are considered important in accepting user's beliefs of an information technology. Meanwhile, ATU directly predicts BI of the users, which determines AU. Later, an extension of TAM or known as TAM2 was proposed by Venkatesh and Davis (2000). As an extension of TAM, TAM2 added a new components namely, output quality, image, job relevance, voluntarism, result demonstrability and subjective norm) and omitted ATU because it is perceived as weak predictors of either BI or AU.

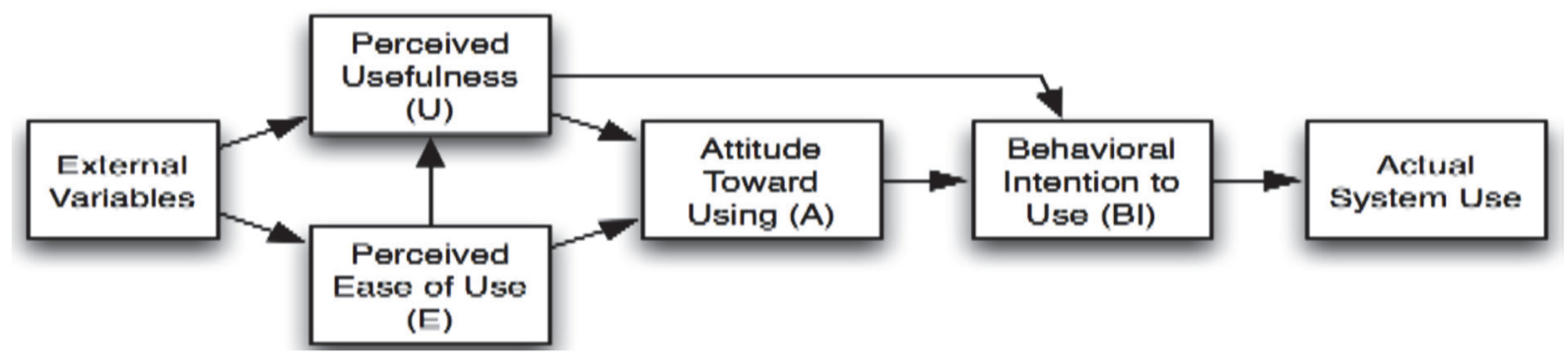

Figure 1. The original TAM (Davis, 1989).

\section{Research Model Factor}

\subsection{Service Quality (SQ)}

Service quality is generally derived from the perspective of customer attitudes, where quality refers to satisfying the requirements of the customer (Geetika \& Nandan, 2010). In terms of successfully fulfilling requirements of customers, Al-Mushasha and Hassan (2009) and El Saghier and Nathan (2013) stated that it based on the ability of the organization to identify and meet these requirements. From viewpoint of the organization, customers must be perceived as persons with individual requirements and in instances where a standard level of service quality is established to satisfy these requirements, organizations that claim to be providing their customers with high-quality services are obliged to satisfy the requirements of their customers. If this can be achieved, the said organization will have positive image in the marketplace, which will give them an edge over their rivals.

As mobile wireless technology increases in terns if capability, the number of institutions like universities that has begun adopting $\mathrm{m}$-learning in their teaching and learning increases. Not only that, as reported by Parsons and Ryu (2006), Al-Mushasha and Hassan (2009) and El Saghier and Nathan (2013), as mobile service quality is regarded as a primary factor linked to user behaviour, measurement of mobile service quality has become important. Thus, it cannot be doubted that knowledge in the factors leading to m-learning service quality can be of value in creating software and hardware design enhancement; this consequently increases the perceived value of the service as well as user satisfaction (Yi et al., 2010). 


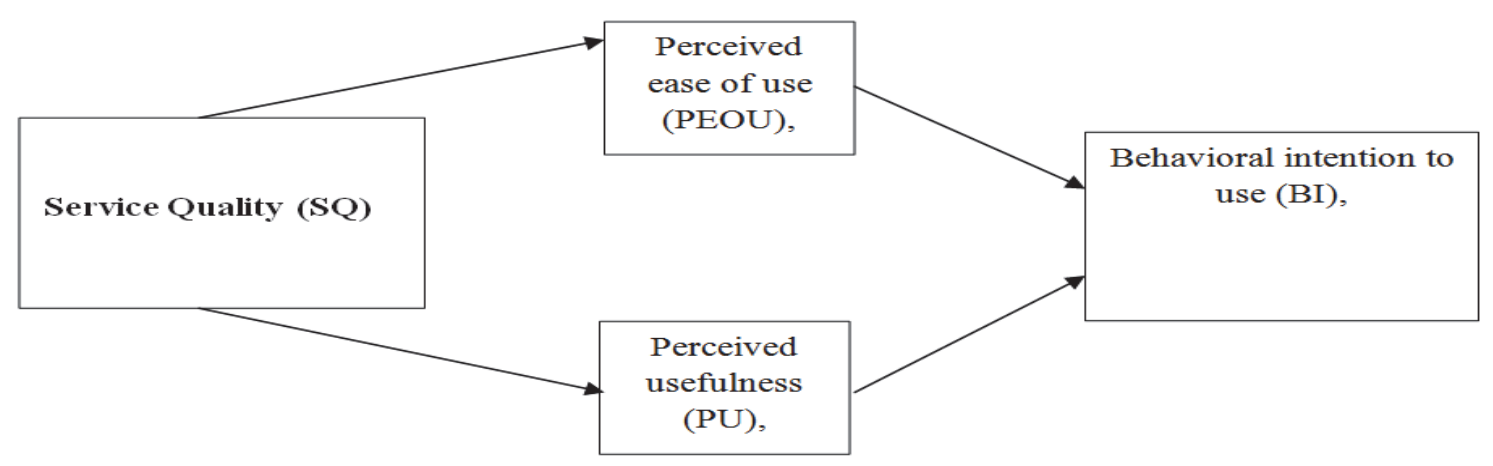

Figure 2. Research Model

\subsection{Research Hypothesis}

H1: Service Quality (SQ) factor has a significant positive relationship with perceived usefulness in the use of mobile learning.

H2: Service Quality (SQ) factor has a significant positive relationship with perceived ease of use to use mobile learning.

H3: Perceived usefulness has a significant positive relationship with behavioral intention to use mobile learning.

H4: Perceived ease of use has a significant positive relationship with perceived usefulness to use mobile learning.

\section{Research Methodology}

This research employed 487 students aged 18 and above enrolling in among Jordanian student as respondents. As for data, they were obtained online (online questionnaires at www.surveyshare.com). There is only one part to the questionnaire. This one part contains items, which represent several constructs. The 5-point scale was chosen for measuring the acceptance level of users. In order to measure the factor that influence to acceptance m-learning among Jordanian students, this study utilized regression analysis. This study attempts to construct an integrated framework with the capacity of measuring the citizen s' readiness to interact with mobile learning. In the investigation of these students readiness, validation to the trust factor with Technology Acceptance Model (TAM) has to be performed.

\subsection{Instrument Development}

As mentioned earlier, the pilot test is performed to ascertain the reliability of the measurement instruments prior to the main empirical study. Meanwhile, as documented by Gay and Airasian (2000), reliability entails the extent to which a test consistently measures whatsoever that is being measured. Further, Cronbach's alpha measures the initial reliability of internal consistency of data that were obtained from pilot study (Cronbach, 1984) and the Cronbach alpha value can be increased in either the average correlation or the number of items (Zander \& Kogut, 1995). Further, it was indicated by Henryson (1971) that an "item-to-total-test correlation should fall between the range of 0.3 to 0.7 for inclusion" in a survey test. After that, a reliability analysis is performed on the full set of data as well as high reliability offered confidence in the results obtained. The reliability analysis vary from 0.70 to 0.80 is the acceptable alpha value for study in general as proposed by Devellis (1991). Table (1.1) illustrations the value of Cronbach's coefficient alpha ranged from .788 to .872 .

Table 1.1 Reliability Coefficient for Multiple Items

\begin{tabular}{lll}
\hline Variable & N. of Items & Alpha (a) \\
\hline Service Quality & 7 & .872 \\
Perceived usefulness & 5 & .901 \\
Perceived ease of use & 5 & .788 \\
\hline
\end{tabular}

\subsection{Data Analysis}

Considering the measurement model, the assessment of the structural model was the subsequent step in the SPSS Analysis; an analysis was performed towards the inner model. Hair et al.'s (2011) proposed requirements were 
perused. Thus, for the testing of hypotheses, the researcher employed bootstrapping to measure the significance level of the path coefficients.

A multiple regression analysis is performed in order to assess the influences between the factors in the proposed research model. All hypotheses test indicate some influences between constructs. The analysis is conducted in three regression models, as shown in Table (1.2). The model contains four hypotheses (H1, H2, H3, and H4).

Table 1.2 Summary of hypotheses

\begin{tabular}{|c|c|c|c|}
\hline Hypotheses & Variable & $\boldsymbol{\beta}$ & Supported \\
\hline H1 & Service Quality ॥|»»» Perceived usefulness & .422 & Yes \\
\hline $\mathrm{H} 2$ & Service Quality ॥"।»» Perceived ease of use & .531 & Yes \\
\hline $\mathrm{H} 3$ & Perceived usefulness "»»»» Behavioral intention to use (BI) & .321 & Yes \\
\hline $\mathrm{H} 4$ & Perceived ease of use "»!)» Behavioral intention to use (BI) & .389 & Yes \\
\hline
\end{tabular}

\section{Discussion and Implications}

This finding is also in line with that by (Abu-Al-Aish and Love 2013), who had come to a conclusion that the factor of service quality positively and significantly impacts behavioral intention, and hence, m-learning acceptance. Aside from that, this finding is also in agreement with Kuruuzum and Koksal (2010) who documented that perceived service quality within the hospitality industry impacts behavioral intention. Thus, owing to its significant effect being widely supported in the literature available, the influence imparted by this factor (the service quality factor) is anticipated. Therefore, it is anticipated that a student who viewed the system of m-learning as functioning, interactive, and responsive will be positively encouraged to effectually involve him/herself in his/her mobile device which will ultimately improve his/her acceptance level. Regarding to the factor of the PU and PEOU, the findings attained demonstrate that the aforesaid factor has positive and significant association with behavioral Intention to Use. This finding is in agreement with those by (Tajudeen et al., 2013; Alzubi et al., 2018) and Jeon et al., (2015). In particular, the findings by (Tajudeen et al., 2013) demonstrate that the factor of perceived usefulness and Perceived ease of use significantly affects the acceptance of student towards mobile learning and it also directly impacts students' behavioral intention to utilise mobile learning. Jeon et al., (2015) support these findings when their recent investigation demonstrates that the factor of Perceived Ease of Use factor is significantly and positively linked with behavioral Intention to Use and therefore should be treated as a vital factor in the Acceptance of Smartphone Application.

\section{Limitation}

As indicated earlier, the findings of this research have verified the findings of the past studies to a certain extent. However, along the work progress, the researcher has discovered and addressed several issues that are worth noting. The study's findings are deemed useful in formulating learning and content management systems design, where technology service quality is concerned. In this regard, system response, accessibility and personalization would prove to be important determining factors in shaping students' acceptance. In short, students may respond positively to m-learning if it is introduced as a learning means with easy access and personalized, user friendly features. Hence, it is the role of system designers to achieve the objective of developing accessible m-learning tools in order to render it appealing to students. Furthermore, there are major effects of the TAM main constructs, particularly in their perceived usefulness, perceived ease of use. To this end, there is no doubt that establishing a more useful and fluid learning management system could heighten students' participation.

\section{Conclusion}

M-learning services are an interesting mode of learning. Additionally, in the setting of higher education, these have become the new crucial platform. To this end, the current research probes into the prerequisites of m-learning services' adoption in the context of higher education setting. The findings obtained demonstrate that both of the environment and the infrastructure that are available at the higher education institutions are suitable for the diffusion of m-learning. Aside from that, the study offers the foundation of knowledge with respect to the current situation of students' awareness with regard to the services of m-learning. Additionally, the study discovered that students do indeed possess sufficient knowledge as well as awareness with respect to such technology adoption in their learning setting. Nonetheless, there are also barriers and obstacles that could impede the actual use of mlearning. Therefore, these should not be taken for granted. However, as found by this research, students were well 
aware of the limitations of m-learning in the context of education.

\section{References}

Abu-al-aish, A., \& Love, S. (2013). Factors Influencing Students' Acceptance of M-Learning: An Investigation in Higher Education. The International Review of Research in Open and Distance Learning, 14(5), 83-108.

Al-matari, A. Y., Iahad, N. A., \& Balaid, A. S. (2013). Factors influencing students' intention to use m-learning. Journal of Information Systems Research and Innovation (JISRII), 5.

Al-Mushasha, N. F., \& Hassan, S. (2009). A Model for Mobile Learning Service Quality in University Environment. International Journal of Mobile Computing and Multimedia Communications, 1(1), 70-91.

Alzaza, N. S., \& Abdul, R. Y. (2010). Student's Mobile Information Prototype (SMIP) for the Higher Education Environment." Proceedings knowledge management fifth international "conference.

Alzaza, N. S., \& Yaakub, A. R. (2011). Students' awareness and requirements of mobile learning services in the higher education environment. American Journal of Economics and Business Administration, 3(1), 95-100.

Alzubi, M. M., Al-Dubai, M. M., \& Farea, M. M. (2018). Using the technology acceptance model in understanding citizens' behavioural intention to use m-marketing among Jordanian citizen. Journal of Business and Retail Management Research, 12(2).

Alzubi, M. M., Alkhawlani, M. A., \& El-Ebiary, Y. A. B. (2017). Investigating the factors affecting University students'e-commerce intention towards: a case study of Jordanian universities. Journal of Business and Retail Management Research, 12(1).

Alzubi, M. M., Farea, M. M., \& Al-Dubai, M. M. (2017). The Mediating Role of Awareness in the Intention to Use Internet Banking Among SMES in YEMEN. The Journal of Internet Banking and Commerce, 22(2), 110.

Davis, F. D. (1986). A Technology Acceptance Model for Empirically Testing New End-User Information Systems: Theory and Results. PhD PhD thesis, MIT Sloan School of Management, Cambridge, MA.

Davis, F. D. P. U. (1989). Perceived Ease of Use, and User Acceptance of Information Technology. MIS Quarterly, 13(3), 319-340.

Devellis, R. (1991). Scale development: Theory and applications. Newbury Park, CA: Sage.

El Saghier, N., \& Nathan, D. (2013, April). Service Quality Dimensions and Customers' Satisfactions of Banks in Egypt. In Proceedings of 20th International Business Research Conference, Dubai, UAE (pp. 4-5).

Embi, M. A., \& Nordin, N. M. (2013). Mobile learning: Malaysian initiatives and research findings. Malaysia: Centre for Academic Advancement, Universiti Kebangsaan Malaysia, 1-131.

Geetika, S. N., \& Nandan, S. (2010). Determinants of customer satisfaction on service quality: a study of railway platforms in India. Journal of Public Transportation, 13(1), 97-113.

Henryson, S. G. (2006). Analysis and using data on test items. In R. L. Thorndike (Ed.), Educational Measurement (2nd ed., pp. 153). Washington, D.C: Council on Education.

Hunt, S., Sparkman Jr, R., \& Wilcox, J. (1982). The pretest in survey research: Issues and preliminary findings. Journal of Marketing Research, 19(2), 269-273.

Iyamu, T., \& Mtshali, E. (2013). Understanding Mobile Technology for Service Delivery in Academic Library. Issues in Information Systems, 14(2).

Jeon, E., \& Park, H. (2015). Factors Affecting Acceptance of Smartphone Application for Management of Obesity. Healthcare Informatics Research, 21(2), 74-82.

Liu, Y., \& Han, S. (2010). Understanding the Factors Driving M-learning Adoption: a Literature Review. CampusWide Information Systems, 27(4), 210-226. https://doi.org/10.1108/10650741011073761

Mtebe, S., \& Raisamo, R. (2014). Investigating students' behavioral intention to adopt and use mobile learning in higher education in East Africa University of Dar es Salaam, Tanzania. International Journal of Education and Development using Information and Communication Technology, 10(3), 4-20.

Parsons, D., \& Ryu, H. (2006). A framework for assessing the quality of mobile learning. Proceedings of the 11th International Conference for Mobile Learning. City, New Zealand. Retrieved from http://citeseerx.ist.psu.edu/viewdoc/download?doi=10.1.1.108.2612\&rep=rep1\&type=pdf

Pimpaka. (2013). Mobile Learning: Designing a Socio-Technical Model to Empower Learning in Higher 
Education." LUX: A Journal of Trans disciplinary Writing and Research from Claremont Graduate University 2.1(2013), 23.

Pulla, S. (2013). E-Learning unplugged: Discovering the potential of a mobile learning movement for Canada. http://www.siomonnpulla.com/2013/10/07/e-learning-unplugged-discovering-potential-mobile-learningmovement-canada/

Shuler, C., Winters, N., \& West, M. (2012). The future of mobile learning: Implications for policy makers and planners.

Tajudeen, S. A., Basha, M. K., Michael, F. O., \& Mukthar, A. L. (2013). Determinant of mobile devices acceptance for learning among students in developing country. The Malaysian Online Journal of Educational Technology, 1(3), 17-29.

Yi, C. C., Liao, P. W., Huang, C. F., \& Hwang, I. H. (2010). Acceptance of mobile learning: A Respecification and Validation of Information System Success. International Journal of Behavioral, Cognitive, Educational and Psychological Sciences, 2(1), 55-59.

Zander, U., \& Kogut, B. (1995). Knowledge and the speed of the transfer and imitation of organizational capabilities: An empirical test. Organization Science, 6(1), 76-92.

\section{Copyrights}

Copyright for this article is retained by the author(s), with first publication rights granted to the journal.

This is an open-access article distributed under the terms and conditions of the Creative Commons Attribution license (http://creativecommons.org/licenses/by/4.0/). 